\title{
NOTES ON FOOD AND FORAGING OF THE HONEY \\ BADGER Mellivora capensis IN \\ THE KALAHARI GEMSBOK NATIONAL PARK
}

\author{
H. KRUUK \\ Institute of Terrestrial Ecology \\ Banchory \\ Kincardineshire $A B 34 B Y$ \\ Scotland
}

M. G. L. MILLS*

Department of Research and Information

Kalahari Gemsbok National Park

Private Bag X5890

Upington

8800

Abstract - Contents of faeces indicated that honey badgers in the Kalahari eat mostly rodents, followed by lizards and scorpions, all of which are caught by digging. Larger mammals (aardwolf, bat-eared fox, springhare) and large snakes are also eaten. Foraging behaviour is described and individual differences in foraging strategies are discussed.

\section{Introduction}

This paper describes preliminary observations on the food and foraging techniques of the honey badger or ratel Mellivora capensis made during October and November 1982 in the Kalahari Gemsbok National Park, Republic of South Africa. Relatively little has been published about the food and feeding habits of the honey badger despite a wealth of anecdotal information, including Stevenson-Hamilton's (1947) descriptions of spectacular feats of predation involving honey badgers killing buffalo Syncerus caffer and blue wildebeest Connochaetes taurinus, by removing the testicles. Smithers (1971) found the remains of scorpions, spiders, rodents and reptiles in five stomachs obtained in Botswana and Stuart (1981) found the remains of a small antelope, a water mongoose Atilax paludinosus and some beetle larvae in three stomachs collected in the Cape Province.

\section{Materials and Methods}

Most information was obtained by following tracks of the honey badgers in the sand, or by combining direct observations and tracking. Tracks of at least eight, probably nine or 10 different honey badgers were followed for a total of $220 \mathrm{~km}$,

\footnotetext{
* New Address

Department of Research and Information

Kruger National Park

Private Bag X402

Skukuza

1350
} 
with the help of a Bushman tracker. Direct observations on undisturbed honey badgers were made from a vehicle or on foot, using $7 \times 50$ binoculars. Eight different animals were watched on 17 occasions, for a total of $13 \mathrm{~h}$; one of these animals had been tagged with a radio collar. This honey badger, a young female, had been caught after a brief chase by car, and by darting and immobilising it using ketamine hydrochloride.

Faeces were collected on the tracks or during direct observations. They were dried. and later washed through a $1,5 \mathrm{~mm}$ mesh sieve. Food remains were then spread out in a dish with water and identified with the unaided eye or under a binocular microscope (magnification 2,4 or $8 x$ ) by comparison with a reference collection of hair, skulls and invertebrates in the Nossob Camp laboratory. For quantification of food remains the method of Kruuk \& Parish (1981) was used; for each dropping it was estimated whether any particular kind of food constituted less than $5 \%$, between 5 and $25 \%$, between 26 and $50 \%$, between 51 and $75 \%$, between 76 and $95 \%$ or more than $95 \%$ in volume of the quantity of food corresponding with that particular sample. The final estimate was calculated as an average of all estimates for individual samples.

All observations were made in an area of approximately $250 \mathrm{~km}^{2}$ around Nossob Camp, described by Mills (1978).
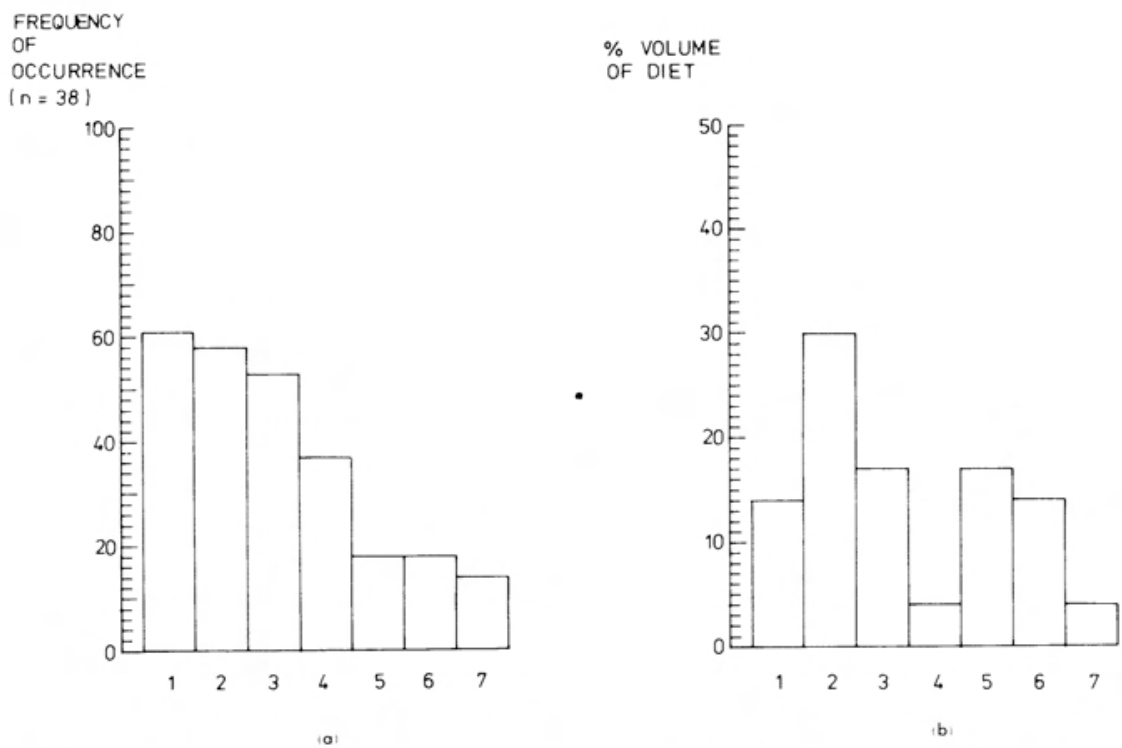

Fig. 1. (a) Percentage frequency with which various food categories occurred in faeces of honey badgers,

(b) estimated percentage volume of these food categories in the actual diet.

$1=$ scorpions, 2 = small rodents, $3=$ lizards and geckoes, $4=$ insects and spiders, 5

= snakes, $6=$ larger mammals, $7=$ birds and eggs. 


\section{Results}

Figure 1 shows the frequency with which various food categories were encountered in the faeces, and their estimated proportion in the total volume of the food. Rodents were by far the most important food, occurring in almost $60 \%$ of the faeces and making up an estimated $30 \%$ of the volume of food. Several species were involved, of which only Tatera brantsii and the ground squirrel Xerus inauris were identified. Springhares Pedetes capensis were included in the category Larger Mammals. Lizards included the skink Mabuya occidentalis and many barking geckoes Ptenopus garrulus; they occurred in more than half the faeces, as did scorpions (several species, mostly more than $100 \mathrm{~mm}$ long), but they were less important in terms of total volume of food. The food category labelled Insects included Hodotermes mossambicus, various Carabid beetles, insect larvae and the odd spider. The snakes that could be identified were large specimens of the common mole snake Pseudaspis cana and adder species. Larger mammals eaten by the honey badgers were aardwolves Proteles cristatus, bat-eared foxes Otocyon megalotis, some unidentified young carnivore (perhaps bat-eared fox) and springhare.

Direct observations on honey badger food included the capture of three rodents and one scorpion (as well as several unidentified small prey). On the tracks the remains (stomachs) were found of 12 small rodents, five large scorpions and a springhare (taken by the honey badger from an African wildcat, Felis lybica). A steenbok Raphicerus campestris was stolen from a brown hyaena Hyaena brunnea just after it had been killed by the hyaena, but later it was retrieved again probably by the original owner. Attempts to catch a bat-eared fox and an aardwolf were unsuccessful.

All the observations of predation attempts on larger mammals, as well as the faeces containing remains of larger mammals, were from one animal, probably a male.

Honey badgers were active at all times except around midday. Nearly all the food, including probably all rodents, scorpions and lizards, was obtained through digging. In the Kalahari sand this is very easy for a honey badger, one could disappear into the ground within 2 minutes. Places where honey badgers started to dig appeared to be found by smell; the animals walked with their nose to the ground, stopping repeatedly. They paid particular attention to bushes (mostly Acacia mellifera var. detinens or A. haematoxylon), and many of the digs were under or alongside one of these bushes. When inspecting such bushes honey badgers approached from downwind ( $94 \%$ of a sample of 50 observations).

Different individuals appeared to use different overall foraging strategies. Most of our observations were of animals which were either known to be or supposed to be females, with or without a cub. They tended to stay in a relatively small area, zigzagging from bush to bush, covering a distance approximately twice as long as that covered by the following vehicle (estimated by walking the track at a speed of approximately $5 \mathrm{~km} / \mathrm{h}$ ). During this "short-distance foraging" the distance covered by the following vehicle was $5,0 \pm 2,8 \mathrm{~km}$ per day $(\mathrm{n}=14)$, so the honey badgers covered an estimated $10 \mathrm{~km}$ per day.

During "long-distance foraging", which we observed especially in one animal, probably a male, the animal changed direction far less often and was more interested in 
larger mammals as food. The distance covered by the following vehicle was about the same as that covered by the honey badger, $27,0 \pm 1,2 \mathrm{~km}$ per day $(\mathrm{n}=3)$. On five days the long-distance foraging honey badger was tracked for less than its complete movement. Taking these partial observations into account as well as the complete ones the difference in distance covered by the two categories of honey badgers is highly significant (Mann-Whitney $\mathrm{U}=3 ; \mathrm{p}<0,001$ ). During short-distance foraging 10,2 holes were dug per $\mathrm{km}$ driven (measured over $70 \mathrm{~km}$ ), whereas during longdistance foraging only 1,3 holes were dug per $\mathrm{km}$ driven (measured over $150 \mathrm{~km}$ ).

The honey badgers slept each day in a different den, often dug for the occasion; only once did an animal re-use a den. The mean straight-line distance between dens from one day to the next was $2,5 \pm 1,6 \mathrm{~km}$ for the short-distance foragers $(n=12)$, and $10,1 \pm 1,6 \mathrm{~km}(\mathrm{n}=2)$ for the long-distance animal. This independence of a fixed home site means that honey badgers may be called nomadic. They did, however, stay within a defined area, at least the short-distance foragers. The radio-collared female and its mother had a range during our study period of $54 \mathrm{~km}^{2}$ (convex polygon); the size of this area did not increase after our first two weeks of observations, so it was probably a good approximation of their home range at least during this time of year. The presumed male, a long-distance forager, moved within a convex polygon of $174 \mathrm{~km}^{2}$, over a period of about 10 days only. As its range was still increasing with the last observations, this is smaller than the actual home-range size.

\section{Discussion}

The various kinds of food which were found to be important in the diet of the honey badger are probably present in the area throughout the year. It is likely, therefore, that Fig. 1 presents a reasonaly accurate picture of the honey badgers' annual diet in the Kalahari, although information from other times of the year is desirable. Our data mostly agree with the few observations from other areas (Smithers 1971; Stuart 1981).

A striking phenomenon in our data is the dichotomy in the size of food items taken by honey badgers, corresponding with very different foraging strategies. On the one hand the animals eat small rodents, scorpions and lizards, and on the other prey such as aardwolves and bat-eared foxes. There are also the reported attacks on large ungulates (Stevenson-Hamilton 1947). It is possible that this is the consequence of individual prey preferences or mere idiosynchrosies. However, in our observations the animal that specialized on larger prey was probably a male, whereas the others were certainly or probably females and the possibility should be investigated that the difference in prey preference is consistent for the sexes, as has been observed in stoats Mustela erminea and weasels M. nivalis (Erlinge 1979; Moors 1980; Pounds 1981).

The nomadic habits of the honey badger are similar to those of the American badger Taxidea taxus, which also changes dens every day, albeit in a smaller range (Sargeant \& Warner 1972), feeding on rodents and occasionally snakes and insects (Lampe 1982). It contrasts sharply with the behaviour of the European badger Meles meles, which returns to the same den every day, foraging from there in different directions for earthworms, insects, vegetable food and carrion (Kruuk 1978; Kruuk \& Parish 1981). To evaluate such differences more information is needed on 
the spatial pattern of food availability and on the importance of the den. It is hoped that further studies on the honey badger will provide an understanding of some of these problems in the desert habitat of the Kalahari.

\section{Acknowledgements}

We are grateful to the National Parks Board of Trustees for allowing us to carry out this study and for assistance of several kinds. Mr M. Rosenberg of Partridge Films Ltd. financed the field work of one of us (H.K.) for which we are very grateful. We also thank Mr E. A. N. le Riche, Dr G. A. Robinson and Mr P. van Wyk for invaluable logistic support, Mr Rikkie Kruiper for his expert tracking. Mrs M. Mills for help with identifying faecal remains, and Dr D. Jenkins for comments on the manuscript.

\section{REFERENCES}

ERLINGE, S. 1979. Adaptive significance of sexual dimorphism in weasels. Oikos 33: 233-245.

KRUUK, H. 1978. Foraging and spatial organisation of the European badger, Meles meles L. Behav. Ecol. Sociobiol. 4; 75-89.

KRUUK, H. and T. PARISH. 1981. Feeding specialisation of the European badger Meles meles in Scotland. J. Anim. Ecol. 50: 773-788.

LAMPE, R.P. 1982. Food habits of badgers in East Central Minnesota. J. Wildl. Manage. 46: 790-795.

MILLS, M.G.L. 1978. Foraging behaviour of the brown hyaena (Hyaena brunnea Thunberg, 1820) in the southern Kalahari. Z. Tierpsychol. 48: 113-141.

MOORS, P.J. 1980. Sexual dimorphism in the body size of mustelids (Carnivora): the role of food habits and breeding systems, Oikos 34: 147-158.

POUNDS, C.J. 1981. Niche overlap in sympatric populations of stoats (Mustela erminea) and weasels ( $M$. nivalis) in North-east Scotland, Ph.D. Thesis, University of Aberdeen.

SARGEANT, A.B. and D.W. WARNER. 1972. Movements and denning habits of a badger. J. Aramms: 33: 207-210. 